\begin{tabular}{|c|l|}
\hline Title & Removal of lead compounds from polyviny Ichloride in electric wires and cables using cation-exchange resin \\
\hline Author(s) & Tsunekawa, Masami; Ito, Mayumi; Sasaki, Y uta; Sakai, Tomoo; Hiroyoshi, Naoki \\
\hline Citation & $\begin{array}{l}\text { Journal of Hazardous Materials, 191(1-3),388-392 } \\
\text { https://doi.org/10.1016/.jhazmat.2011.04.098 }\end{array}$ \\
\hline Issue Date & 2011-07-15 \\
\hline Doc URL & http://hdl.handle.net/2115/46915 \\
\hline Type & article(author version) \\
\hline File Information & JHM191-1-3_388-392.pdf \\
\hline
\end{tabular}

Instructions for use 


\section{Removal of lead compounds from polyvinylchloride in electric wires and cables using cation-exchange resin}

Masami Tsunekawa ${ }^{1}$, Mayumi Ito ${ }^{1}$, Yuta Sasaki ${ }^{1}$, Tomoo Sakai ${ }^{1}$, and Naoki Hiroyoshi ${ }^{1}$

1) Division of Sustainable Resources Engineering, Faculty of Engineering, Hokkaido University, Kita 13 Nishi 8, Kita-ku, Sapporo , 0608628, JAPAN

Corresponding author: M. Ito, itomayu@eng.hokudai.ac.jp

Tel\&Fax: 011-706-6315 
Abstract: Recycling treatment of cable insulation resin generated from electric wires and cables was investigated. Conventional insulation PVC contains a lead component, tribase, as a thermal stabilizer and lead removal is necessary to recycle this PVC as insulation resin. This paper describes a solid surface adsorption method using ion exchange resin to remove the fine lead containing particles from PVC dissolved solution. Low lead concentration in the recovered PVC, complying with the requirements of RoHS, was achieved.

Key words: polyvinylchloride, recycling, lead removal, cation-exchange resin

\section{INTRODUCTION}

Used electric wires and cables recovered from electric power suppliers and building wreckers in Japan are cut to liberate and separate into metal conductors and cable insulation for recycling. Cable insulation is made of several kinds of resin: polyvinylchloride (PVC), polyethylene (PE), and cross-linked polyethylene (XLPE) and the PVC is most common. The amount of collected cable insulation per year is 36,000 tons and the collection ratios of mixed plastics is high $(44.1 \%)$, followed by PVC at $25.1 \%$ in Japan [1]. Material recycling of mixed plastic is difficult and most is discarded in landfills. Thus plastic-plastic separation methods have been investigated [2] and electrostatic separation techniques have been used in cable insulation plastic treatment [3]. The authors $[4,5]$ have applied jig separation methods to cable insulation plastics, PVC, and non-PVC and reported high separation efficiencies. Single component resin pellets of PVC and PE, crushed used cable insulation, are sold as recyclable pellets, for use in the production of flooring and seat plastics and other usages [6], since these 
pellets do not meet required performance criteria as cable insulation.

Mizuno et al. [7] has calculated $\mathrm{CO}_{2}$ emissions from PVC cable insulation manufacture and reported that reductions of $31 \%$ of $\mathrm{CO}_{2}$ can be achieved when used PVC is mixed with virgin PVC (virgin: recycled pellets $=7: 3$ ). Murata et al. [8] has developed a kneading method for virgin PVC and used PVC mixing and reported that the blended product can be used for only sheathing of electric wires and cables since volume resistivity is lower than the performance required for cable insulation.

The PVC cable insulation contains lead compounds as a thermal stabilizer [9] and the use of toxic substances such as lead is regulated strictly by RoHS (Restriction of Hazardous Substances in electric and electronic equipment) in the EU. In RoHS, lead concentrations in electric and electronic equipment must be below 1,000 ppm. Alternatives to lead compounds like hydrotalcite have been developed [10], however the development of lead removal methods for waste PVC in cable insulation is needed to recycle used insulation as a raw material for cable insulation since formerly produced cable insulation contains lead compounds. The Vinyloop method [11] is one method to recycle PVC resin. Here PVC is first dissolved in an organic solvent and PVC and additives are recovered with a deposition method by steam injection after removal of large impurities. The used organic solvent is recovered by a salting-out method and reused. In the Vinyloop method removal of lead compounds is difficult because the lead compounds are very fine particles (average size $<2 \mu \mathrm{m}$ ).

To remove the lead compounds some methods have been investigated, including filtration, leaching methods [12], and liquid liquid interface trapping [13], but technical problems such as plugging of filters and the treatment of leaching solution are remaining. This paper describes a solid surface adsorption method using ion exchange 
resin to remove the fine lead containing particles from dissolved PVC solution. The treatment is divided into three steps and a pretreatment method involving ion exchange resin was developed.

\section{MATERIALS AND METHODS}

\subsection{Materials}

Virgin cable insulation PVC was used in the experiments. This sample contains tribasic lead sulfate (tribase, $3 \mathrm{PbO} \mathrm{PbSO}_{4} \mathrm{H}_{2} \mathrm{O}, \mathrm{Pb}$ concentration: 17,600 ppm) and calcium carbonate $\left(\mathrm{CaCO}_{3}, \mathrm{Ca}\right.$ concentration: 120,000 ppm). Methyl ethyl ketone (MEK, Daishin Chemical Corporation) was used as organic solvent. Strong acid cation exchange resin (15JWET, $\mathrm{H}^{+}$type, Rohm and Haas Company) was used as adsorbent. Hydrochloric acid, sodium chloride, potassium chloride, magnesium chloride, calcium chloride, and aluminum chloride (Wako Pure Chemical Industries, Ltd.) were used for the pretreatment of the resin.

\subsection{Methods}

Fig. 1 shows an outline of the lead removal treatment processes from PVC and the treatment is divided into three steps, a pretreatment process for ion exchange resin, dissolution and centrifugation step for PVC, and a lead removal process.

In the pretreatment process, $20 \mathrm{~cm}^{3}$ of ion exchange resin was added to $200 \mathrm{~cm}^{3}$ of $0.1 \mathrm{M}$ of various chloride solutions (some experiments with $1 \mathrm{M}$ of hydrochloric acid), and after 1 hour the supernatant was replaced by $200 \mathrm{~cm}^{3}$ of distilled water and agitated by plastic spatula (PTFE) for rinsing. This rinse treatment by distilled water was repeated three times. Then the ion exchange resin was rinsed by MEK, here $20 \mathrm{~cm}^{3}$ of ion exchange resin was added to $30 \mathrm{~cm}^{3}$ of MEK and hand shaken at $30 \mathrm{~cm}$ of 
amplitude in capped bottles and then the supernatant was drained. This rinsing by MEK was repeated six times. The solution conductivity of the supernatant from the last MEK rinsing was measured by a conductivity meter (CM-30G, DKK-TOA Corporation).

In the dissolution and centrifugation process, PVC was added to MEK and dissolved at $80{ }^{\circ} \mathrm{C}$ for 2 hours agitated at 1,200 rpm by impeller, at a 5\% PVC volume ratio to MEK. This PVC dissolved solution was centrifuged at $1,000 \mathrm{G}$ for 1 minute to remove particulate matter including calcium carbonate. The lead concentration of the supernatant after the centrifugation was $8,080 \mathrm{ppm}(17,600 \mathrm{ppm}$ in the feed).

After centrifugation, $20 \mathrm{~cm}^{3}$ of the pretreated ion exchange resin was put into 30 $\mathrm{cm}^{3}$ of the centrifuged supernatant and agitated using a bottle roller (mix rotor VMR, AS ONE Corporation) at $120 \mathrm{rpm}$ for 15 minutes. After agitation, the liquid was separated from the ion exchange resin by sieve (openings $100 \mu \mathrm{m}$ ) and placed on a petri dish for drying. Drying was carried out in two stages, first: at room temperature for 12 hours in a draft chamber, and next: at $70{ }^{\circ} \mathrm{C}$ for 12 hours in an oven. The lead concentration of the dried PVC sample was measured by inductively coupled plasma analysis after acid digestion, $0.2 \mathrm{~g}$ of shredded PVC was added to $8 \mathrm{~cm}^{3}$ of nitric acid ( $60 \mathrm{wt} \%$ conc.) and this was treated by a microwave digestion method.

\section{Results and discussion}

According to RoHS the lead concentration in recovered PVC must be below $1,000 \mathrm{ppm}$ to allow use as cable insulation. The PVC sample here contains tribase $(\mathrm{Pb}$ concentration: 17,600 ppm) and calcium carbonate (Ca concentration: 120,000 ppm) and the particle diameter is $1-2 \mu \mathrm{m}$ for tribase and $4-5 \mu \mathrm{m}$ for calcium carbonate. Most of the calcium carbonate can be removed by centrifugation at $1,000 \mathrm{G}$ for $1 \mathrm{~min}$. In this 
study removal of the remaining fine lead particles by an adsorption method was investigated.

\subsection{Tribase attachment on ion exchange resin as solid particles}

Some adsorbents like glass, minerals, and several kinds of ion exchange resin (cation types and anion types) were tested and strong acidic cation exchange resin (15JWET, Rohm and Haas Company) showed superior lead removal properties under appropriate conditions as will be described in 3.2.

In general the main role of ion exchange resin is adsorption of ions from solutions by ion exchange. However, the tribase here is present as solid particles and the solubility of lead ions in MEK is low. To confirm the low solubility of lead here, tribase was added to MEK and MEK containing 5 mass $\% \mathrm{H}_{2} \mathrm{O}$ solutions and the lead concentrations of the supernatants were measured. The values of lead ion concentrations in MEK were below $4 \mathrm{ppm}$ and the dissolution ratios were below $0.3 \%$, suggesting that the contribution through this process is small.

Fig. 2 shows microscopic images of the ion exchange resin with tribase attached and this suggests that tribase attaches on the ion exchange resin as solid particles.

\subsection{Effect of pretreatment of ion exchange resin}

Pretreatment conditions of the ion exchange resin were investigated. The surface of ion exchange resin changes with the ions adsorbed on the resin. In this study ion exchange resin after the pretreatment described in Fig.1 was used. In the pretreatment process, various chlorides $\left(\mathrm{KCl}, \mathrm{NaCl}, \mathrm{MgCl}_{2}, \mathrm{CaCl}_{2}\right.$, and $\left.\mathrm{AlCl}_{3}\right)$ were dissolved separately into water at $0.1 \mathrm{M}$ and the ion exchange resin was treated in these chloride solutions. After the pretreatment the ion exchange resin was added to the PVC dissolved solution to remove the tribase particles. In the lead removal process described in Fig.1, 
the pretreated ion exchange resin was added to the supernatant generated by the centrifugation and the values of the lead concentrations in the recovered PVC are shown in Fig. 3. In this test, the values in the same conditions (the reproducibility) varied with the tests and Fig. 3 shows the lowest lead concentration values achieved. The values were below 1,000 ppm with the pretreatments with $\mathrm{MgCl}_{2}$ and $\mathrm{AlCl}_{3}$ and $0.1 \mathrm{M} \mathrm{HCl}$ also showed values below 1,000ppm.

\subsection{Effect of MEK rinsing of ion exchange resin}

In the PVC dissolved MEK solution, PVC is deposited by water addition since the solubility of PVC with MEK decreases with increasing water content. Thus ion exchange resin pretreated in chloride solutions requires rinsing by MEK to remove adhered water as described in 2.2 and then his resin was used in the lead removal tests. To elucidate the effect of rinsing on the variability of the lead concentration values, the conductivity of the MEK solution used in the last rinsing was measured. Fig. 4 shows the relationship between the electric conductivity of the MEK used for the last rinsing and the lead concentration in the recovered PVC. The lead concentration decreased with increasing conductivity and low lead concentrations, below $1000 \mathrm{ppm}$, was obtained at over $0.2 \mathrm{mS} / \mathrm{m}$ of conductivity regardless of the kind of adsorbed cation. Pretreatment with $1 \mathrm{M}$ of hydrochloric acid was also tested and this showed low lead concentrations and high conductivity. It was found that the conductivity of the solution used for the last rinsing can be used as an indicator of lead removal efficiency.

\subsection{Adsorption mechanism of tribase on ion exchange resin}

The results detailed above show that ion exchange resin pretreated under appropriate conditions can adsorb tribase. In this section, the adsorption mechanism is discussed. Particle-particle interaction force in solutions $(\mathrm{F})$ is shown as equation 1 . The 
effects of these forces were investigated.

$\mathrm{F}=\mathrm{F}_{\mathrm{el}}+\mathrm{F}_{\mathrm{A}}+\mathrm{F}_{\text {chem. }}+\mathrm{F}_{\text {others }} \quad$ (Equation 1)

$\mathrm{F}_{\mathrm{el} .}$ : electrostatic interaction force, $\mathrm{F}_{\mathrm{A}}$ :van der Waals' force, $\mathrm{F}_{\text {chem. }}$ : chemical interaction force, $F_{\text {others }}$ : other effects

The surface charge affects the electrostatic interaction force. The zeta potential of tribase shows a negative charge [14] and tests using calcite mineral having a positive charge were carried out (the values of the zeta potential of calcite in the MEK containing $\mathrm{HCl}$ solution $(0.4 \mathrm{mS} / \mathrm{m})$ were 5.40 and that of tribase was $-4.56 \mathrm{mV})$. However the lead concentration in the recovered PVC with calcite was about $5000 \mathrm{ppm}$ and this indicates that the effect of the electrostatic attraction force is small.

Tribase shows a negative charge in MEK, cation exchange resin is also negatively charged in MEK and the attachment of tribase on the resin is difficult. However compression of the electric double layer thickness of tribase causes a reduction in the absolute values of the zeta potential and would make attachment possible by decreasing the electric repulsion force. The electric double layer thickness is compressed by increasing the ionic strength in solutions. The authors have reported that the electric conductivity of MEK solutions increases with increasing $\mathrm{H}_{2} \mathrm{O}$ and electrolyte (like $\mathrm{NaCl}$ and $\mathrm{KNO}_{3}$ ) content [14]. Fig. 5 shows the electric conductivity of MEK solutions containing different concentrations of hydrochloric acid (the amount of added hydrochloric acid solution is 1 mass $\%$ for MEK and the value of ' $0 \mathrm{M}$ ' shows the conductivity of the MEK containing 1 mass $\%$ of $\mathrm{H}_{2} \mathrm{O}$ ) showing that the electric conductivity increases with increasing concentrations of hydrogen ions. To investigate the effect of the electric conductivity of solutions used in the $\mathrm{Pb}$ removal process, MEK 
containing $\mathrm{HCl}$ solutions (the amount of added hydrochloric acid solution is 1 mass $\%$ for MEK) was substituted for MEK in the 'PVC dissolution process' described in Fig.1. In the 'lead removal process', the ion exchange resin, showing the electric conductivity of the MEK used in the last rinsing to be below $0.2 \mathrm{mS} / \mathrm{m}$, was used as adsorbent. Fig. 6 shows the relationship between the lead concentration in the recovered PVC and the electric conductivity of the MEK containing $\mathrm{HCl}$ solutions used in the 'PVC dissolution process'. As shown in Fig. 4, ion exchange resin showing an electric conductivity of the last rinsing to be less than $0.2 \mathrm{mS} / \mathrm{m}$ did not achieve a lead concentration below 1000 ppm. However the lead concentration was below $1000 \mathrm{ppm}$ when the electric conductivity of the MEK containing $\mathrm{HCl}$ solutions used for the $\mathrm{PVC}$ dissolution process was above $0.2 \mathrm{mS} / \mathrm{m}$. This confirms that decreasing the electric repulsion force is required and that a high ionic strength in the 'PVC dissolved solutions' is effective for lead removal.

The correlation between the electric conductivity of the last rinsing solution and lead concentration of the recovered PVC shown in Fig. 4 can be explained with the above results. The electric conductivity of the MEK used for the last rinsing may be affected by the amount of cation desorbed from the ion exchange resin. In general the amount of desorbed cations from an ion exchange resin is proportional to the amount of cations adsorbed on the ion exchange resin and this suggests that ion exchange resins showing high lead removal (lead content [is] below 1,000 ppm) retain more cations after rinsing.

Based on equation 1, the obtained results show that the chemical interaction force $\left(F_{\text {chem. }}\right)$ and van der Waals' force $\left(F_{A}\right)$ may affect the attachment of tribase on ion exchange resin. Ion exchange resin is composed of a substrate polymer and functional 
groups and the effects of these were investigated. Synthetic adsorbent made of the same organic polymer substrate as the ion exchange resin was tested and here the resulting lead concentration was $5380 \mathrm{ppm}$. This suggests that lead removal is not affected by the properties of the substrate but by the functional groups. The functional group of the used ion exchange resin is a sulfo group. The coefficient of ion selectivity of lead ions for the sulfo groups of this resin is higher than those of other ions [15] and this may suggest that tribase adsorbs on the ion exchange resin by chemical adsorption forces.

Overall it was found that chemical interaction is important and that decreasing the electric repulsion force assists in the attachment of tribase on ion exchange resin. Thus, high levels of lead removal can be achieved with solutions with high electric conductivity used in the lead removal process and by the use of ion exchange resin including sulfo groups.

\section{Conclusions}

Removal of fine lead particles by a solid surface adsorption method was investigated. Some adsorbent compounds were tested and strongly acidic cation exchange resin showed superior results. Electron microscopic observations showed the attachment of tribase particles on the ion exchange resin. Rinsing of ion exchange resin in the pretreatment process causes variability in the lead removal results and it was found that the electric conductivity of the MEK used for the last rinsing can be used as an indicator of lead removal efficiency. Low lead concentrations, below 1,000 ppm, were achieved above a value of $0.2 \mathrm{mS} / \mathrm{m}$ of conductivity in the MEK. Using MEK containing $\mathrm{HCl}$ for the PVC dissolution process also improved lead removal. 
It was found that chemical interaction forces are important and that decreasing the electric repulsion force assists the attachment of tribase on ion exchange resin. High levels of lead removal can be achieved with a high electric conductivity of the solution used in the lead removal process and by using ion exchange resin containing sulfo groups. 


\section{References}

[1] T. Gotoh, S. Ashihara, T. Yamazaki, K. Watanabe, Recycling of electric wires and cables, Symposium on dielectrics and electronical insulating materials, 38 (2007) 199-200.

[2] M. Ito, M. Tsunekawa, Recent developments in plastic-plastic separation techniques, Journal of MMIJ, 122 (2006) 142-149.

[3] T. Kumagai, T. Ishikawa, Y. Nagao, A. Nakayama, T. Enami, Used wires and cable recycling system established for contribution to recycling society, the Hitachi densen, 21 (2002) 107-110.

[4] K. Hori, M. Tsunekawa, N. Hiroshi, M. Ito, Optimum water pulsation of jig separation for crushed plastic particles, Int. J. Miner. Process. 92 (2009) 103-108.

[5] K. Hori, M. Tsunekawa, M. Ueda, N. Hiroyoshi, M. Ito, H. Okada, Development of a new gravity separator for plastics -a Hybrid jig-, Materials Transactions, 50 (2009) 2844-2847.

[6] M. Maruyama, Current status in development of cable recycling technology, Electrical review, 6 (2004) 36-41.

[7] K. Mizuno, H. Hirukawa, LCA study for insulated wires, Furukawa electric review, 104 (1999) 13-18.

[8] K. Murata, K. Aida, S. Ooya, Y. Tominaga, T. Matsumoto, K. Mizuno, H. Motomiya, Development of insulated wire and cable using recycling PVC, Furukawa electric review, 110 (2002) 11-14.

[9] Vinyl Environmental Council (Ed.), PVC Fact book, Tokyo, 2005

[10] S. Koube, Current status of environmental friendly PVC, Polyfile, 2007.8 (2007) 
27-31.

[11] Solvay S. A., Toku Kai 11-310660 (Japan patent)

[12] T. Ezure, K. Goto, Current status and tasks in development of cable recycling technology, IEEJ Trans. PE, 124 (2004) 1276-1280.

[13] M. Tsunekawa, J. Mimura, T. Sakai, N. Hiroyoshi, M. Ito, Liquid liquid interface trapping of lead containing fine particles, Proc. MMIJ Annual Meeting Vol. II (2009) $115-116$

[14] M. Tsunekawa, Y. Sasaki, Y. Nakamura, M. Ito, N. Hiroyoshi, K. K. Yoo, Dispersion-Flocculation Behavior of Fine Lead Particles in an Organic Solvent Materials Transactions, 49 (2008) 1276-1280.

[15] K. Ooi , Muki ion koukantai, NTS, Tokyo, 2010 (in Japanese) pp. 55-60. 
Figures

Fig. 1 Flowchart of the lead removal treatment process.

Fig. 2 Electron microscopic images of ion exchange resin with tribase attached. (a) whole image and (b) magnified image, the white part shows $\mathrm{Pb}$ compounds.

Fig. 3 Lead concentration in the recovered PVC using various chloride solutions for pretreatment of ion exchange resin.

Fig. 4 Relationship between the lead concentration in the recovered PVC and the electric conductivity of the MEK used in the last rinsing of the ion exchange resin.

Fig. 5 The electric conductivity of the $\mathrm{HCl}$ containing MEK solutions (the amount of added hydrochloric acid solution is 1 mass $\%$ for MEK and the value of ' $0 \mathrm{M}$ ' shows the conductivity of the MEK containing 1 mass $\%$ of $\mathrm{H}_{2} \mathrm{O}$ ).

Fig. 6 Relationship between the lead concentration in the recovered PVC and the electric conductivity of the $\mathrm{HCl}$ containing $\mathrm{MEK}$ solutions used in the dissolution process (the amount of added hydrochloric acid solution is 1 mass $\%$ for MEK). 


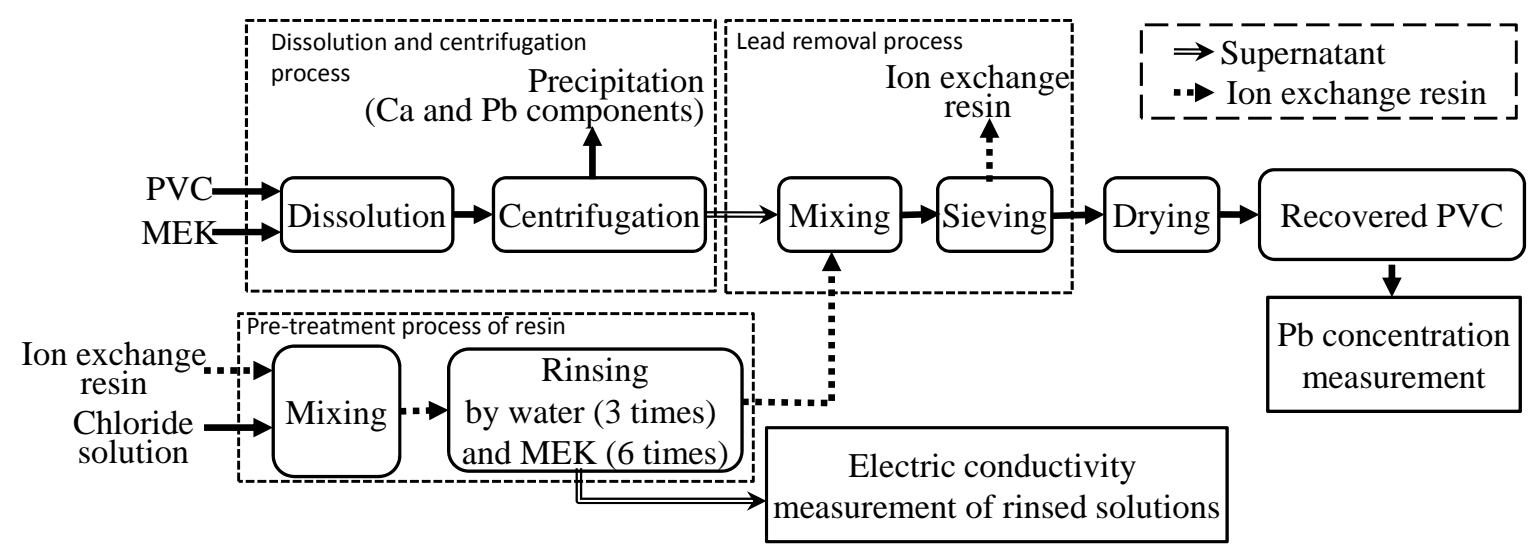

Fig. 1 Flowchart of the lead removal treatment process. 


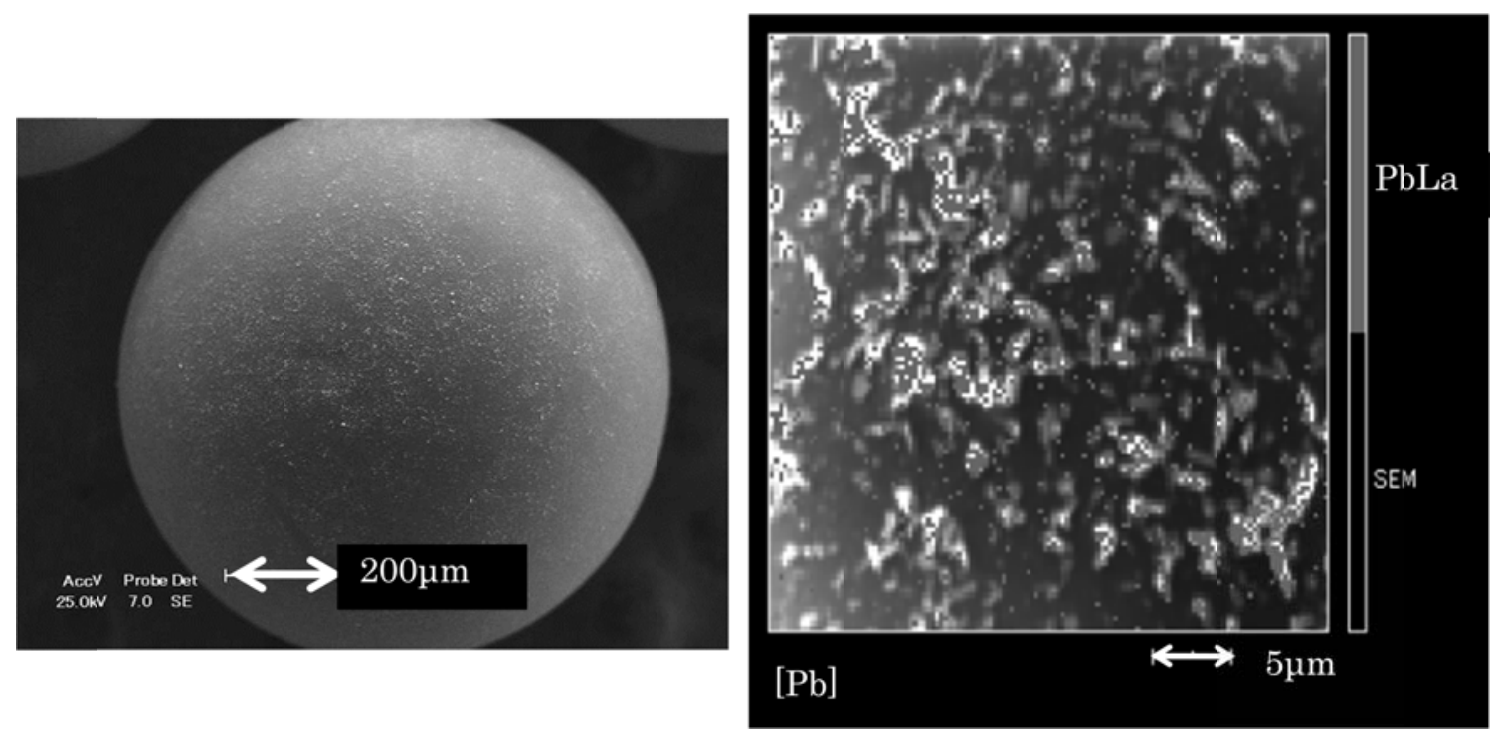

Fig. 2 Electron microscopic images of ion exchange resin with tribase attached. (a) whole image and (b) magnified image, the white part shows $\mathrm{Pb}$ compounds. 


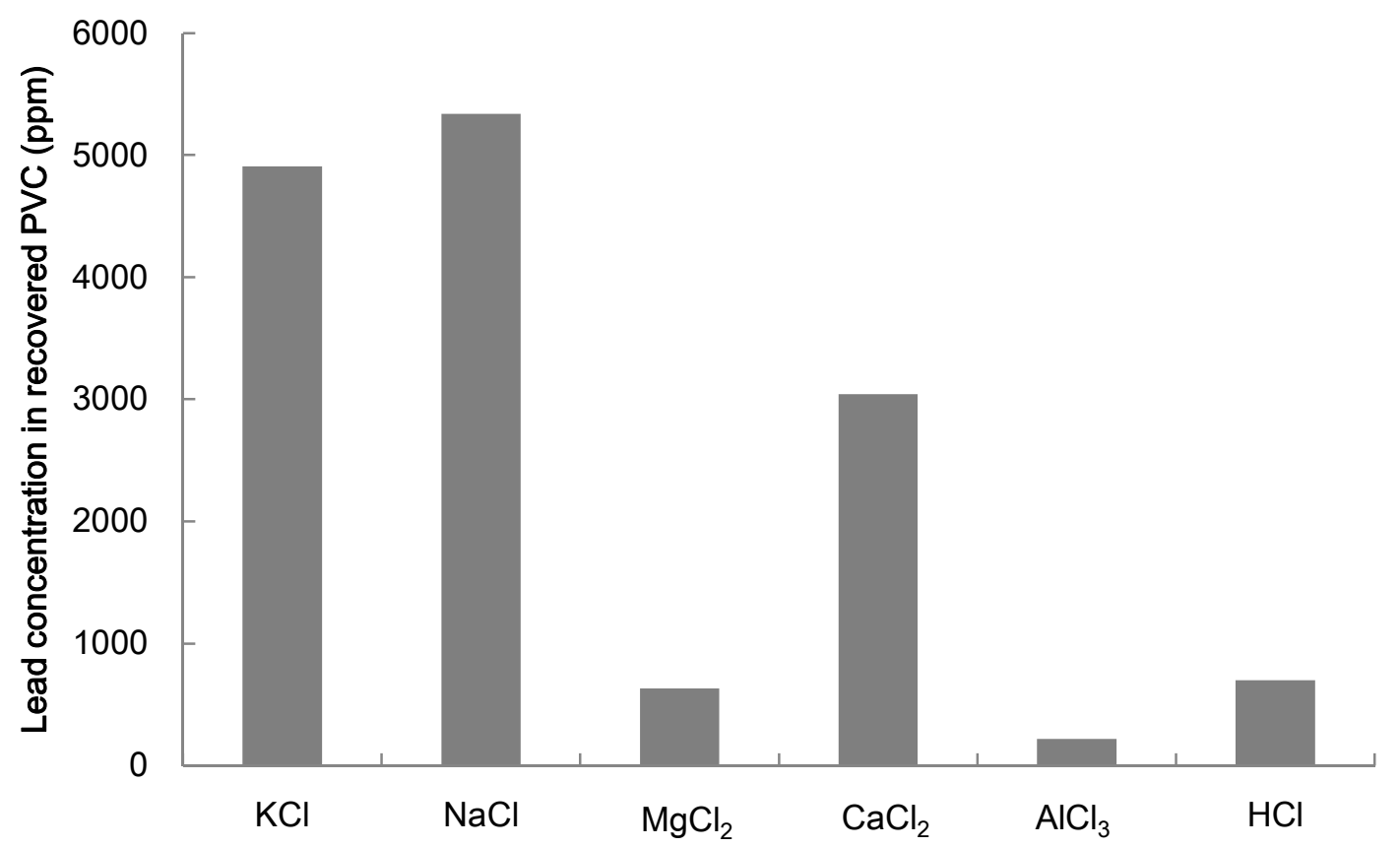

Fig. 3 Lead concentration in the recovered PVC using various chloride solutions for pretreatment of ion exchange resin. 


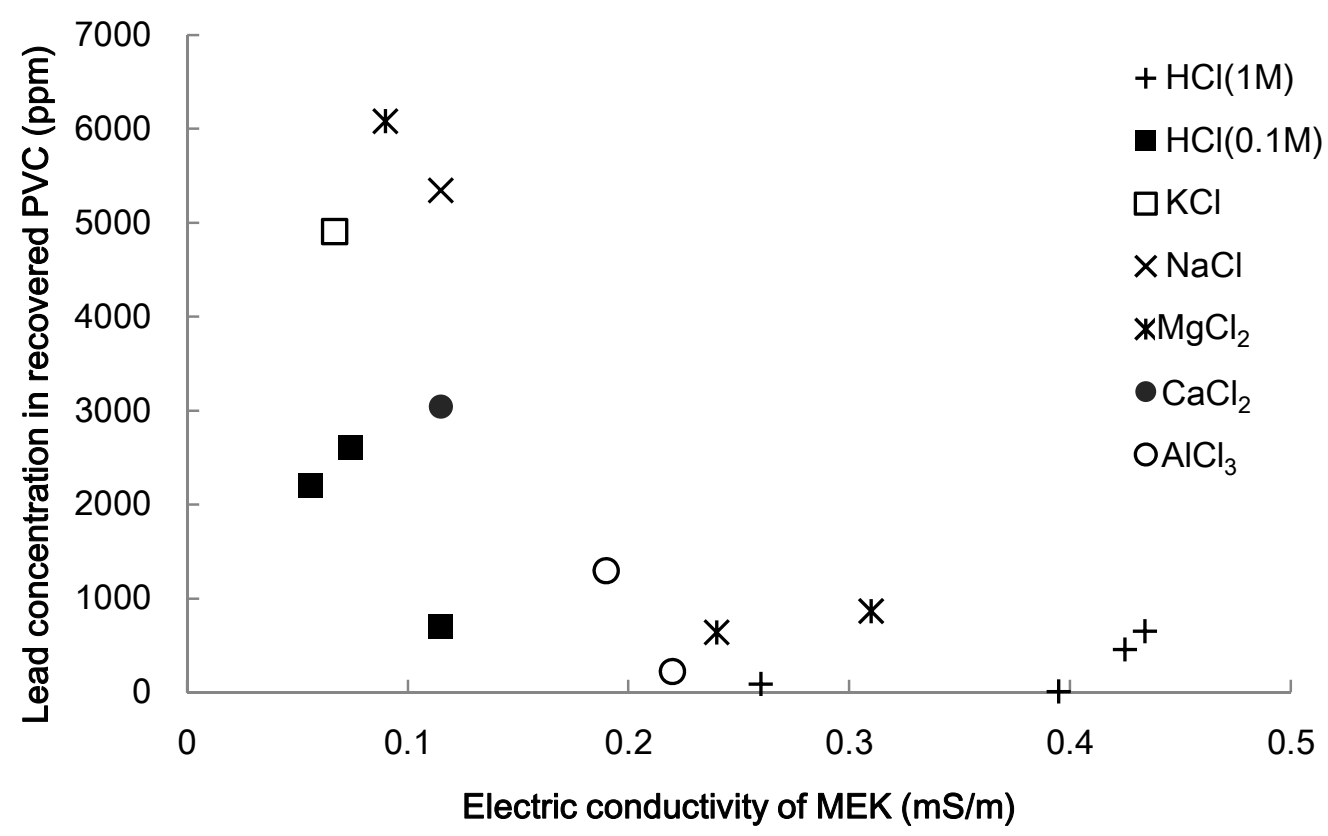

Fig. 4 Relationship between the lead concentration in the recovered PVC and the electric conductivity of the MEK used in the last rinsing of the ion exchange resin. 


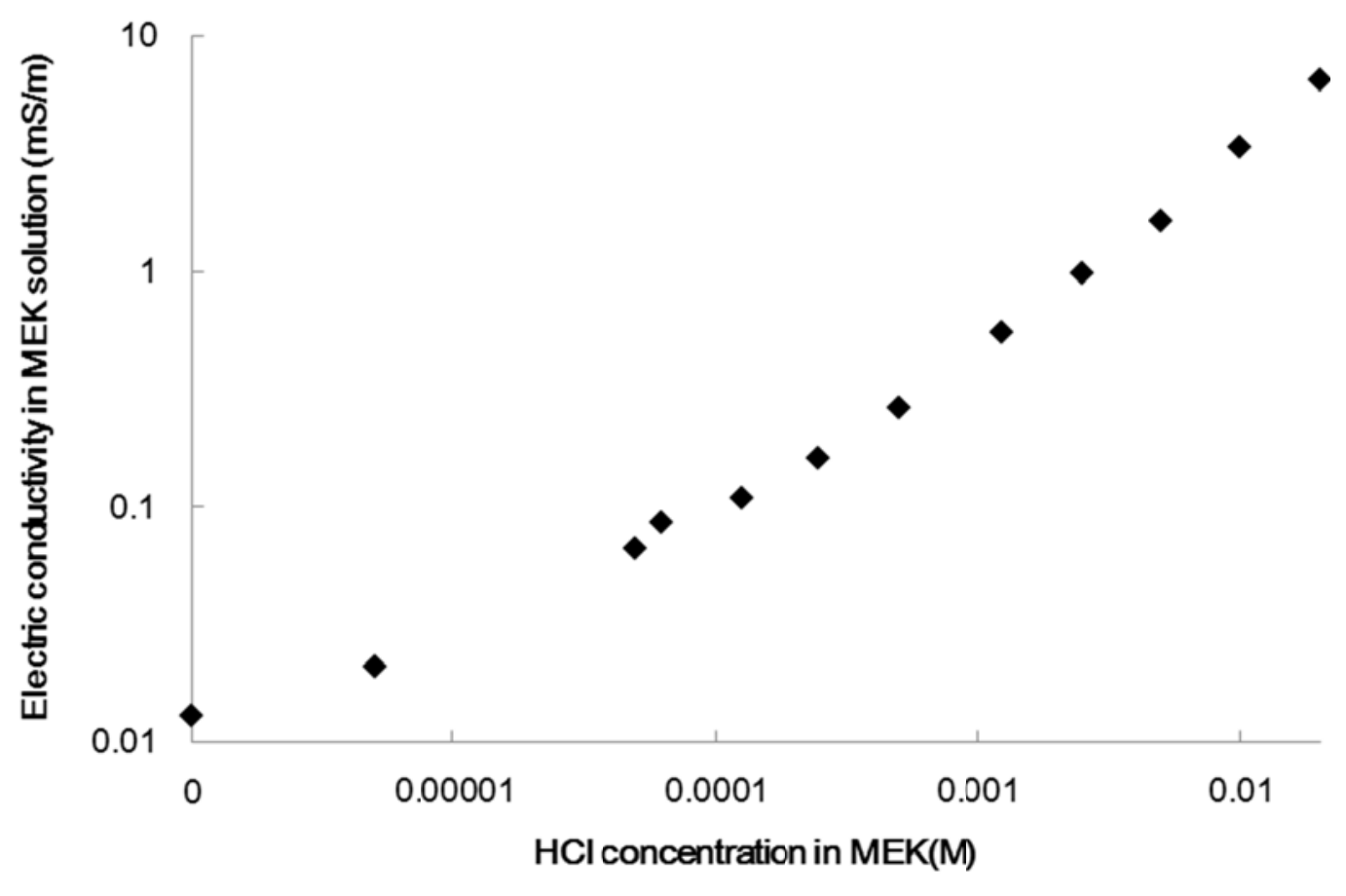

Fig. 5 The electric conductivity of the $\mathrm{HCl}$ containing MEK solutions (the amount of added hydrochloric acid solution is 1 mass\% for MEK and the value of ' 0 M' shows the conductivity of the MEK containing 1 mass $\%$ of $\mathrm{H}_{2} \mathrm{O}$ ). 


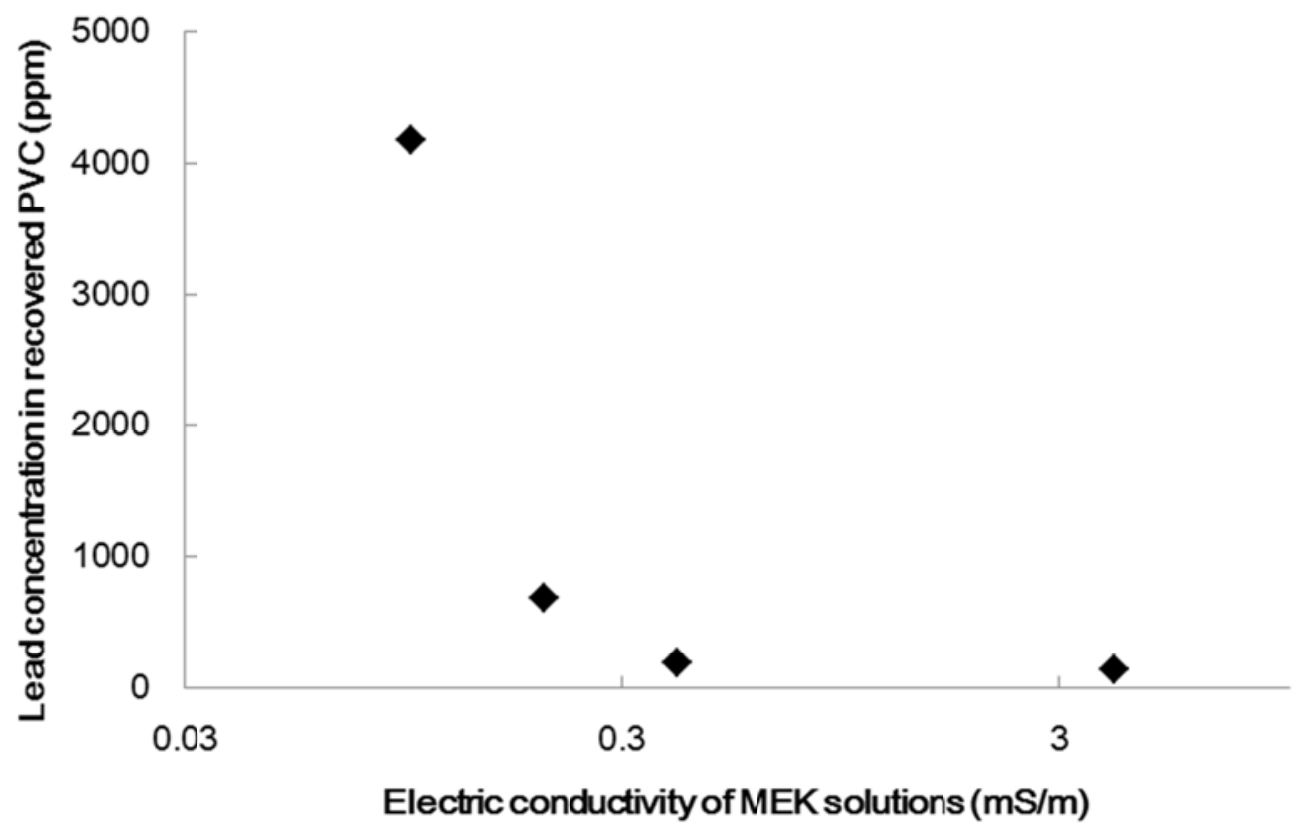

Fig. 6 Relationship between the lead concentration in the recovered PVC and the electric conductivity of the $\mathrm{HCl}$ containing MEK solutions used in the dissolution process (the amount of added hydrochloric acid solution is 1 mass\% for MEK). 